\title{
Demonstration of the Impact of Thermomagnetic Processing on Cast Aluminum Alloys
}

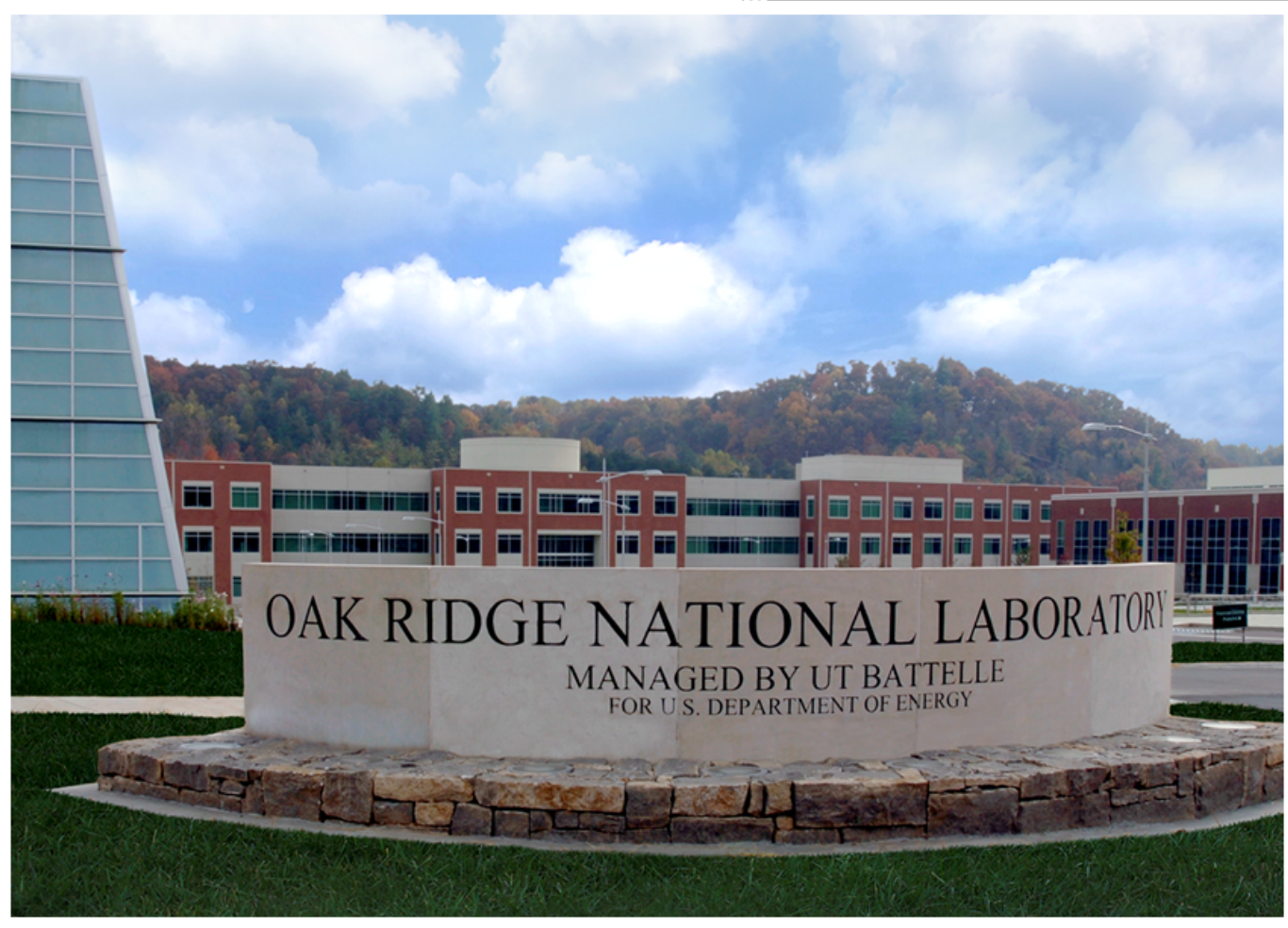

Gerard M. Ludtka Michael S. Kesler Hunter B. Henderson Orlando Rios Bart L. Murphy

September 29, 2017 


\title{
DOCUMENT AVAILABILITY
}

Reports produced after January 1, 1996, are generally available free via US Department of Energy (DOE) SciTech Connect.

Website http://www.osti.gov/scitech/

Reports produced before January 1, 1996, may be purchased by members of the public from the following source:

\author{
National Technical Information Service \\ 5285 Port Royal Road \\ Springfield, VA 22161 \\ Telephone 703-605-6000 (1-800-553-6847) \\ TDD 703-487-4639 \\ Fax 703-605-6900 \\ E-mail info@ntis.gov \\ Website http://www.ntis.gov/help/ordermethods.aspx
}

Reports are available to DOE employees, DOE contractors, Energy Technology Data Exchange representatives, and International Nuclear Information System representatives from the following source:

Office of Scientific and Technical Information

PO Box 62

Oak Ridge, TN 37831

Telephone 865-576-8401

Fax 865-576-5728

E-mail reports@osti.gov

Website http://www.osti.gov/contact.html

This report was prepared as an account of work sponsored by an agency of the United States Government. Neither the United States Government nor any agency thereof, nor any of their employees, makes any warranty, express or implied, or assumes any legal liability or responsibility for the accuracy, completeness, or usefulness of any information, apparatus, product, or process disclosed, or represents that its use would not infringe privately owned rights. Reference herein to any specific commercial product, process, or service by trade name, trademark, manufacturer, or otherwise, does not necessarily constitute or imply its endorsement, recommendation, or favoring by the United States Government or any agency thereof. The views and opinions of authors expressed herein do not necessarily state or reflect those of the United States Government or any agency thereof. 
ORNL/TM-2017/500

CRADA/NFE-15- 05869

Materials Science \& Technology Division

Advanced Manufacturing Office

\title{
Demonstration of the Impact of Thermomagnetic Processing on Cast Aluminum Alloys
}

\author{
Gerard M. Ludtka \\ Michael S. Kesler \\ Hunter B. Henderson \\ Orlando Rios \\ Bart L. Murphy \\ David Weiss
}

Date Published:

September 29, 2017

\author{
Prepared by \\ OAK RIDGE NATIONAL LABORATORY \\ Oak Ridge, Tennessee 37831-6283 \\ managed by \\ UT-BATTELLE, LLC \\ for the \\ US DEPARTMENT OF ENERGY \\ under contract DE-AC05-00OR22725
}

Approved For Public Release 



\section{CONTENTS}

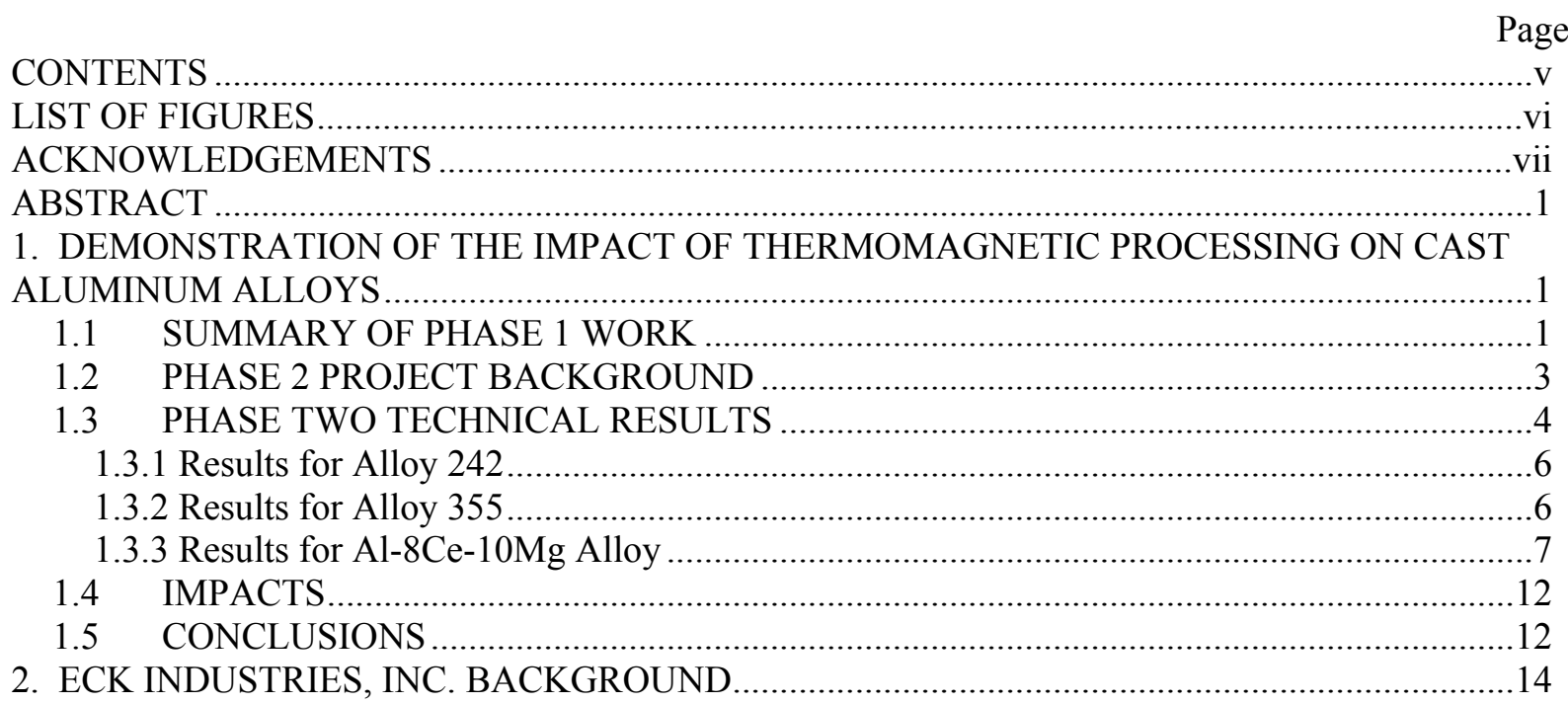




\section{LIST OF FIGURES}

Figure 1. An Al-Ce-Mg alloy cylinder head mounted on an engine for in-situ testing and characterization at ORNL's Spallation Neutron Source (https://m.phys.org/news/2017-07-neutronspeer.html).

Figure. 2 ORNL's 5-inch diameter, vertical warm-bore 9 Tesla superconducting magnet system used

for the aluminum thermomagnetic processing experiments.

Figure 3. Optical micrographs of alloy 242 in the untreated (left) and thermomagnetically processed (right) conditions.

Figure 4. Optical micrographs of alloy 355-T6 in the untreated (left) and thermomagnetically processed (right) conditions.

Figure 5. Optical (top) and SEM BSE (bottom) micrographs of alloy Al-8Ce-10Mg in the as-cast (left), HIP (middle), and thermomagnetically processed (right) conditions.

Figure 6. Optical micrographs of thermomagnetically processed alloy Al-8Ce-10Mg showing pinning of some $\mathrm{Al} / \mathrm{Al}$ grain boundaries.

Figure 7. SEM BSE micrographs of alloy Al-8Ce-10Mg showing the effect of processing on the morphology of a Fe-rich phase.

Figure 8. Phase fraction vs temperature diagram for the Al-8Ce-10Mg composition.......................10 Figure 9 Concept drawing provided by Cryogenic Limited for an 8-tesla, cryogen-free (conduction cooled) 16-inch $(406 \mathrm{~mm})$ diameter warm-bore superconducting magnet system.

Figure 10 Concept drawing provided by AMI, Inc. for a 2-tesla, recondensing cryocooler-based, 24inch $(610 \mathrm{~mm})$ diameter warm-bore superconducting magnet system. 


\section{ACKNOWLEDGEMENTS}

This CRADA NFE-15- 05869 was conducted as a Technical Collaboration project within the Oak Ridge National Laboratory (ORNL) Manufacturing Demonstration Facility (MDF) sponsored by the US Department of Energy Advanced Manufacturing Office (CPS Agreement Number 24761).

Opportunities for MDF technical collaborations are listed in the announcement "Manufacturing Demonstration Facility Technology Collaborations for US Manufacturers in Advanced

Manufacturing and Materials Technologies" posted at http:/web.ornl.gov/sci/manufacturing/docs/FBO-ORNL-MDF-2013-2.pdf. The goal of technical collaborations is to engage industry partners to participate in short-term, collaborative projects within the Manufacturing Demonstration Facility (MDF) to assess applicability and of new energy efficient manufacturing technologies. Research sponsored by the U.S. Department of Energy, Office of Energy Efficiency and Renewable Energy, Advanced Manufacturing Office, under contract DE-AC0500OR22725 with UT-Battelle, LLC. 


\begin{abstract}
This project builds on an earlier Manufacturing Demonstration Facility Technical Collaboration phase 1 project to investigate application of high magnetic fields during solution heat treating and aging of three different cast aluminum alloys. The alloys processed via thermomagnetic processing (TMP) were the 242,355 , and $\mathrm{Al}-8 \mathrm{Ce}-10 \mathrm{Mg}$ alloys. Mechanical property results from cast tensile samples heat treated in ORNL's 5-inch, vertical-bore 9 Tesla (T) superconducting magnet system clearly indicate a 10 to $65 \%$ increase in yield strength (YS) and 16 to $37 \%$ increase in ultimate tensile strength (UTS) over reported conventional heat treatment practice values depending on the alloys system. All of the TMP solution heat treating and aging times employed in this study were for times significantly shorter than those conventionally required by industrial practice to achieve equal or better tensile mechanical performance. TMP offers a path to lower cost/energy materials processing with no loss of mechanical performance and the potential for property improvement. Microstructural analyses suggest that the high magnetic fields enable faster dissolution of solute during the solution heat treating cycle. Faster dissolution would be manifest as finer and more copious strengthening precipitates after the aging cycle which would explain the increase in YS and UTS without loss of ductility via TMP.

Briefly presented and discussed are concept drawings for two different, large-bore superconducting magnet systems that could handle production scale parts. Based on the availability of these systems in the current marketplace, commercial implementation of TMP, especially at the $2 \mathrm{~T}$ magnetic field level, can be realized if a return-on-investment calculation supported that path forward. The results of this study on multiple different alloy systems clearly demonstrate that the TMP technology achieves enhanced room temperature mechanical property performance at significantly shorter processing times compared with conventional heat treating practices. Of significance from a commercial implementation perspective, magnetic fields on the order of $2 \mathrm{~T}$ appear to have similar beneficial effects as field strengths up to $9 \mathrm{~T}$ for the Al-8Ce-10Mg alloy, which suggests lower magnetic field strengths may improve mechanical properties of other age hardening aluminum alloy systems for both cast and wrought product.
\end{abstract}

\title{
1. DEMONSTRATION OF THE IMPACT OF THERMOMAGNETIC PROCESSING ON CAST ALUMINUM ALLOYS
}

This phase 2 technical collaboration project (MDF-TC-15- 011) was begun on September 17, 2015 and was completed on September 17, 2017. The collaboration partner Eck Industries, Inc. is a small business. The overarching impact of this project is that TMP technology is shown to achieve excellent enhanced room temperature mechanical property performance at significantly shorter processing times compared with conventional heat treating practices for cast aluminum alloys. A non-provisional U.S. patent application covering this technology breakthrough was submitted during the scope of this endeavor and is referenced as footnote 1 .

\subsection{SUMMARY OF PHASE 1 WORK}

Phase 1 of this Manufacturing Demonstration Facility Technical Collaboration project was completed prior to the phase two work which was done under this CRADA. In Phase 1, ORNL staff worked with Eck Industries, Inc. to reduce heat treatment times from fourteen hours to four hours for cast 
aluminum alloy A206 processed in a magnetic field using ORNL's 5-inch, horizontal 9T superconducting magnet system, while retaining or increasing mechanical properties. These results demonstrated improved energy efficiency via reduced processing times required for heat treatment, as well as the potential for improved material properties. These phase 1 results warranted further development of this technology to enable industrial implementation. For the purposes of this Phase 2 report, some background results from that Phase 1 effort are shown below that formed the basis for submission in February 2017 of a non-provisional US patent application (footnote1) to protect this breakthrough intellectual property technology.

To evaluate the new TMP processing method, aluminum alloy A206 samples of standard chemistry that were obtained in the as-cast and T4 (solution treated only) conditions underwent thermomagnetic processing to the $\mathrm{T} 7$ condition (solution treatment plus aging). A horizontal magnet with a 5-inch bore at ORNL was employed at a magnetic field strength of 9 Tesla. The T4 and T7 nomenclature used above corresponds to standard temper practices and designations as defined by the Aluminum Association.

The as-cast samples underwent a solution treatment at either $510^{\circ} \mathrm{C}$ or $530^{\circ} \mathrm{C}$ for two hours. In the phase 1 work aging times for solution treated samples in the T4 condition were varied among 30 minutes, one hour and two hours to determine the impact of reduced treatment times during exposure to the magnetic field. For brevity, only the 2 hour aging conditions are summarized in Tables 1 and Table 2. Processed samples were then tested for ultimate tensile strength (UTS), yield strength (YS) and \% elongation using conventional mechanical test methods. The results of the mechanical tests are summarized in Table 1 with the corresponding processing conditions for those samples detailed in Table 2 .

Table 1 Treatment Times and Conditions with Mechanical Properties for the A206 Alloy

\begin{tabular}{|c|c|c|c|c|c|c|c|}
\hline Alloy ID & $\begin{array}{c}\text { Solution } \\
\text { Time } \\
\text { (min) }\end{array}$ & $\begin{array}{c}\text { Solution } \\
\text { Field }\end{array}$ & $\begin{array}{c}\text { Aging } \\
\text { Time } \\
\text { (min) }\end{array}$ & $\begin{array}{c}\text { Aging } \\
\text { Field }\end{array}$ & $\begin{array}{c}\text { Tensile } \\
\text { Strength } \\
\text { (ksi) }\end{array}$ & $\begin{array}{c}\text { Yield } \\
\text { Strength } \\
\text { (ksi) }\end{array}$ & $\begin{array}{c}\text { Elongation } \\
\%\end{array}$ \\
\hline $\begin{array}{c}\text { T4 } \\
\text { Standard }\end{array}$ & 600 & NF & N/A & N/A & 50.0 & 30.0 & 10.0 \\
\hline $\begin{array}{c}\text { T7 } \\
\text { Standard }\end{array}$ & 600 & NF & 240 & NF & 50.0 & 40.0 & 3.0 \\
\hline As Cast 1 & 120 & $\mathbf{9 ~ T}$ & N/A & N/A & 55.9 & 47.8 & 3.5 \\
\hline As Cast 2 & 120 & $\mathbf{9}$ T & 120 & $\mathbf{9 ~ T}$ & 58.2 & 51.1 & 3.0 \\
\hline As Cast 3 & 120 & $\mathbf{9}$ T & 120 & $\mathbf{9}$ T & 62.8 & 50.0 & 5.5 \\
\hline
\end{tabular}

$\mathbf{N F}=$ No Field, $\mathbf{N A}=$ Not Applicable

Table 2 Summary of Processing Conditions for the A206 Aluminum Alloy

\begin{tabular}{|l|l|}
\hline Alloy ID & Processing Conditions \\
\hline T4 Standard & $8-12 \mathrm{~h}$ at $530^{\circ} \mathrm{C}\left(985^{\circ} \mathrm{F}\right), \mathrm{NF}$ \\
\hline T7 Standard & $\mathrm{T} 4$ plus $4 \mathrm{~h}$ at $200^{\circ} \mathrm{C}, \mathrm{NF}$ \\
\hline As Cast 1-T4 & $510^{\circ} \mathrm{C}$ for $2 \mathrm{~h}, 9 \mathrm{~T}, \mathrm{WQ}$ \\
\hline As Cast 2-T7 & $\mathrm{T} 7: 530^{\circ} \mathrm{C}, 9 \mathrm{~T}, 2 \mathrm{~h}, \mathrm{WQ} ; 200^{\circ} \mathrm{C}, 2 \mathrm{~h}, 9 \mathrm{~T}$ \\
\hline As Cast 3-T7 & $\mathrm{T} 7: 530^{\circ} \mathrm{C}, 9 \mathrm{~T}, 2 \mathrm{~h}, \mathrm{WQ} ; 200^{\circ} \mathrm{C}, 2 \mathrm{~h}, 9 \mathrm{~T}, \mathrm{FC}$ \\
\hline
\end{tabular}

$\mathbf{W Q}=$ Water Quench, $\mathbf{N F}=$ No Field, $\mathbf{F C}=$ Furnace Cool

1 "Method of Thermomagnetically Processing an Aluminum Alloy", Ludtka, G.M., Rios, Orlando, and Weiss, David, USPTO non-provisional patent application number 20170226617, published August 10, 2017. 
For samples supplied in the as-cast condition, full solution occurred within two hours under the magnetic field, which is less than $20 \%$ of the standard 10 -hour cycle time. This was verified through the mechanical properties data, which show that ultimate tensile strengths of above $55 \mathrm{ksi}(379 \mathrm{MPa})$ and yield strengths above $47 \mathrm{ksi}(324 \mathrm{MPa})$ can be achieved after significantly reduced solution processing times when a $9 \mathrm{~T}$ magnetic field is applied.

\subsection{PHASE 2 PROJECT BACKGROUND}

Phase 2 of the project was designed to build from the phase 1 results to explore other aluminum alloys with an additional goal of evaluating even lower magnetic field strengths to find the threshold value needed to provide shortened processing times while giving equivalent or better mechanical properties. For this project, both a 2xx series Al-Cu (alloy 242) and a 3xx series Al-Si-Cu alloy (alloy $355)$ were processed. The $2 \mathrm{xx}$ alloy series has excellent mechanical properties both at room and elevated temperature, but can be difficult to cast in complicated geometries because the alloys contain no $\mathrm{Si}$.The 3xx series alloys are currently used for the production of automotive cylinder heads produced by Eck Industries. Existing alloys like 319 contain $6 \% \mathrm{Si}$ and $3.5 \% \mathrm{Cu}$ and are capable of only moderate room temperature and elevated temperature strength. Alloys such as 356 contain higher levels of $\mathrm{Si}$ and $\mathrm{Mg}$ but no $\mathrm{Cu}$. These alloys have excellent room temperature strength but poor strength at elevated temperature.

There is high potential to reach strength targets in 3xx series alloys that contain both high levels of Si (up to $9 \%$ ) and $\mathrm{Cu}$ (up to 5\%). Conventional treatment of this type of alloy is especially difficult as the $\mathrm{Cu}$ content requires long solution treatment times, which can cause coarsening of the silicon particles. The accelerated kinetics of magnetic processing may allow large amounts of copper into solution in times short enough to prevent coarsening of the silicon particles.

Additionally in phase 2, the effect of magnetic field processing on the major ORNL-developed breakthrough Al-8Ce-10Mg alloy was explored. The Al-Ce-X (footnote 2) alloy systems hold significant promise of improved mechanical properties over the A206 alloy system studied earlier, and would represent a major market impact for Eck and the broad aluminum casting industry. Eck Industries Inc. obtained an exclusive license from ORNL. These new alloys have superb elevated temperature (up to $500^{\circ} \mathrm{C}$ ) strength and microstructural stability. For example, as demonstrated in a DOE Advanced Manufacturing Office sponsored Critical Material Institute project on the Al-8Ce$10 \mathrm{Mg}$ alloy in the T6 condition, this alloy generally shows a $24.5 \mathrm{ksi}$ YS, $32 \mathrm{ksi}$ UTS and $2 \%$ elongation. If performance over that behavior can be achieved with magnetic processing, that would be significant especially in light of enhanced engine performance demonstrated for a cast Al-8Ce$10 \mathrm{Mg}$ alloy cylinder head as shown in Figure 1.

\footnotetext{
2 "Castable High-Temperature Ce-Modified Al Alloys", Rios, Orlando, et al, USPTO non-provisional patent application number 20170096730, published April 6, 2017.
} 


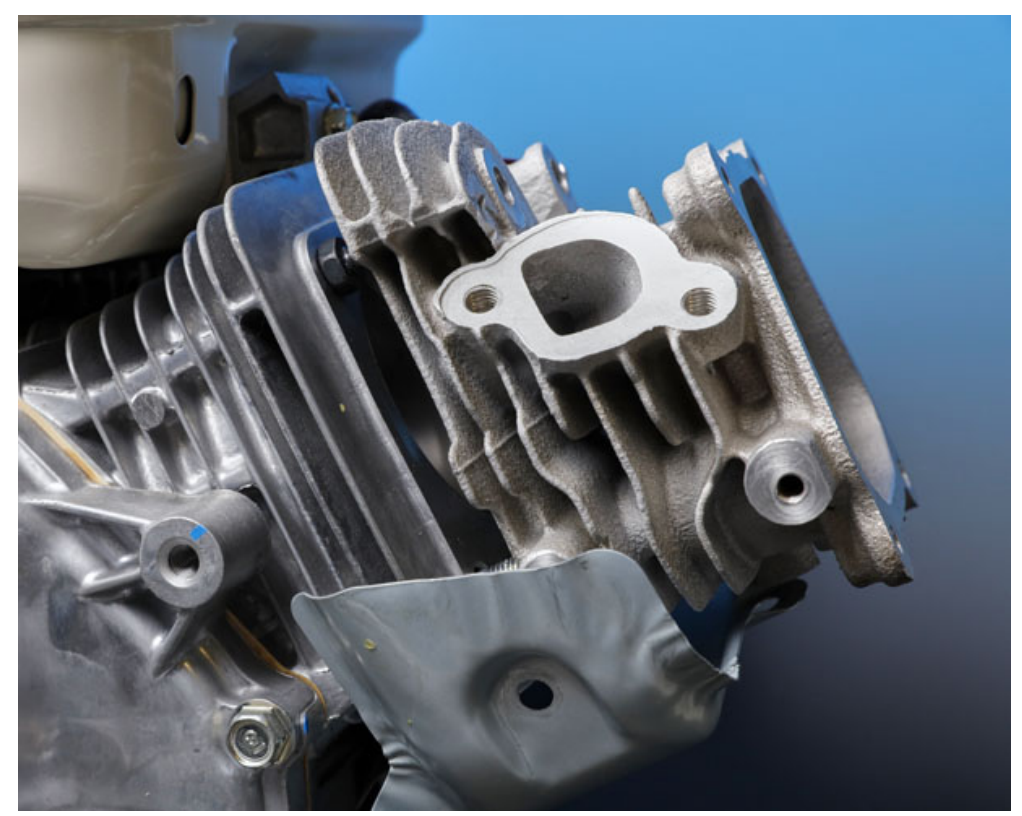

Figure 1. An Al-Ce-Mg alloy cylinder head mounted on an engine for in-situ testing and characterization at ORNL's Spallation Neutron Source (https://m.phys.org/news/2017-07-neutrons-peer.html).

\subsection{PHASE TWO TECHNICAL RESULTS}

Thermomagnetic processing was accomplished in ORNL's 5-inch diameter, vertical warm-bore $9 \mathrm{~T}$ superconducting magnet system with a 9-inch long uniform magnetic field zone. That system is shown in Figure 2. A graphite susceptor approximately 2-inch in outer diameter (OD) with a 1.25 inch inner diameter (ID) was used to provide uniform heating to each sample. The susceptor was contained in a 2.2-inch ID closed end quartz tube and positioned in an induction heating coil insert positioned inside the magnet bore in the uniform magnetic field zone. A carbon fiber thread was tied to the sample as a means of extraction for the rapid water immersion quench immediately following the solution heat treatment. The water quench consisted of a four gallon reservoir of room temperature water. The cooled sample was then removed from the bath and returned to the susceptor to be aged.

A summary of the tensile test data TMP processed samples as provided by Eck are shown in Table 3 . Included with these data are additional reference data to provide comparison with the conventional mechanical properties including data achieved with the Al-8Ce-10Mg alloy through the Critical Material Institute (CMI) program on these alloys. The CMI data are for a conventional T6 temper heat treatment, and for a sample that received a hot isostatic pressing (HIP) step that is generally used on materials to reduce porosity and increase density. The CMI sample data are highlighted in blue at the bottom, right of Table 3. Two rows in Table 3 are highlighted in yellow as these results have uncharacteristically low yield strength and ultimate tensile strength not typical of this alloy system. Casting defects may be the cause of the low values so those data points will not be discussed further in this report. A general comment is that experimental results generated in the CMI project show that the $\mathrm{T} 6$ temper does not provide any improvement in mechanical properties for the Al-8Ce-10 $\mathrm{Mg}$ alloy over the typical as-cast properties of $27 \mathrm{ksi}$ YS, $33 \mathrm{ksi}$ UTS, and 1\% elongation. The no-field T6 temper does little for this alloy other than provide a little more homogenization with the result of slightly lower properties. Factoring in all of these results from this MDF project and the ongoing CMI 
program makes the thermomagnetic processing technology even more impressive for performance enhancement in these cast alloys.

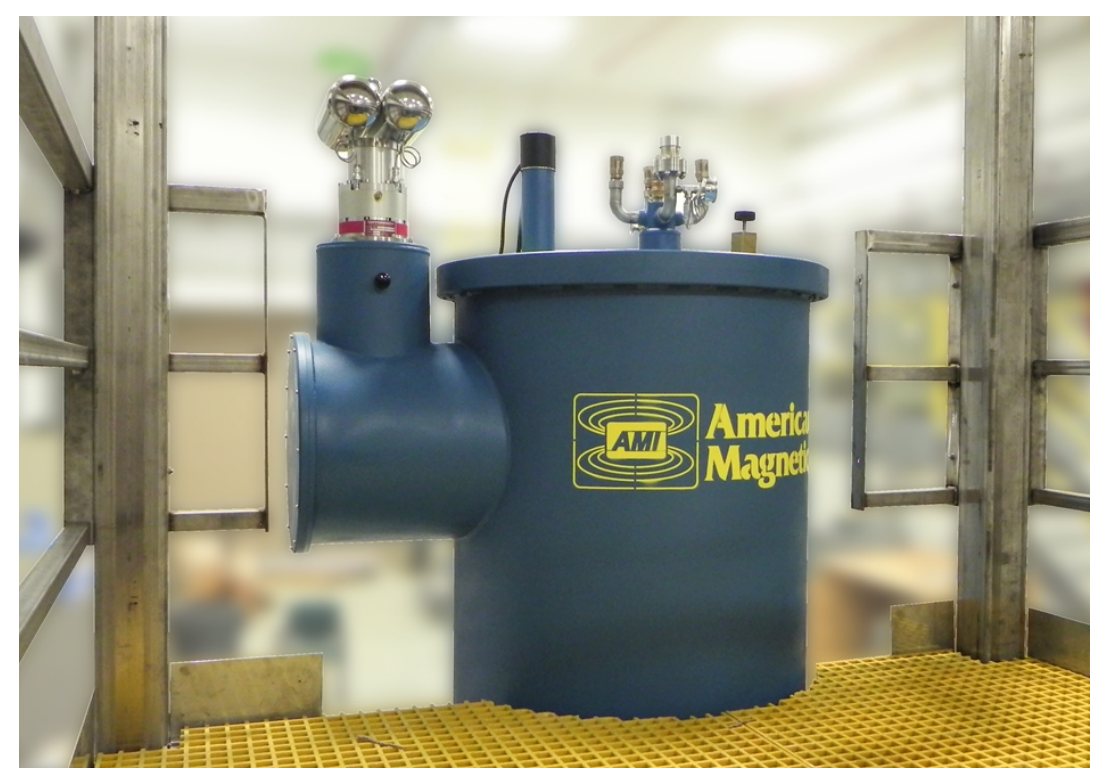

Figure. 2 ORNL's 5-inch diameter, vertical warm-bore 9 Tesla superconducting magnet system used for the aluminum thermomagnetic processing experiments.

Table 3 Thermomagnetic Processing and Resultant Mechanical Property Details

\begin{tabular}{|c|c|c|c|c|c|c|c|c|c|}
\hline Alloy & Field & Solution & Time & Quench & Age & Time & $\begin{array}{l}\text { UTS } \\
\text { (ksi) }\end{array}$ & $\begin{array}{c}\text { YS } \\
\text { (ksi) }\end{array}$ & $\%$ EI \\
\hline 242 & $9 \mathrm{~T}$ & $516^{\circ} \mathrm{C}$ & $2 \mathrm{hrs}$. & Water & $205^{\circ} \mathrm{C}$ & $1 \mathrm{hr}$. & 39.5 & 38.4 & 1.2 \\
\hline & $9 \mathrm{~T}$ & $516^{\circ} \mathrm{C}$ & $2 \mathrm{hrs}$. & Water & $205^{\circ} \mathrm{C}$ & $1 \mathrm{hr}$. & 41.4 & 38.8 & 1.25 \\
\hline $\begin{array}{c}\text { 242-T77 } \\
\text { Typical Lit. }\end{array}$ & & & & & & & 30.0 & 23.0 & 1.0 \\
\hline 355 & $9 \mathrm{~T}$ & $527^{\circ} \mathrm{C}$ & $2 \mathrm{hrs}$. & Water & $154^{\circ} \mathrm{C}$ & $1 \mathrm{hr}$. & 41.2 & 28.8 & 3.28 \\
\hline & $9 \mathrm{~T}$ & $527^{\circ} \mathrm{C}$ & $2 \mathrm{hrs}$. & Water & $154^{\circ} \mathrm{C}$ & $1 \mathrm{hr}$. & 41.6 & 29.1 & 2.3 \\
\hline $\begin{array}{c}\text { 355-T6 } \\
\text { Typical Lit. } \\
\end{array}$ & & & & & & & 35.0 & 25.0 & 3.0 \\
\hline 8Ce10Mg & $9 \mathrm{~T}$ & $500^{\circ} \mathrm{C}$ & $2 \mathrm{hrs}$. & Water & $155^{\circ} \mathrm{C}$ & $1 \mathrm{hr}$. & 36.5 & 30.5 & 1.15 \\
\hline & $9 \mathrm{~T}$ & $500^{\circ} \mathrm{C}$ & $2 \mathrm{hrs}$. & Water & $155^{\circ} \mathrm{C}$ & $1 \mathrm{hr}$. & 17.7 & 5.6 & 1.02 \\
\hline & $5 \mathrm{~T}$ & $500^{\circ} \mathrm{C}$ & $2 \mathrm{hrs}$. & Water & $155^{\circ} \mathrm{C}$ & $1 \mathrm{hr}$. & 37.4 & 30.5 & 2.47 \\
\hline & $5 \mathrm{~T}$ & $500^{\circ} \mathrm{C}$ & $2 \mathrm{hrs}$. & Water & $155^{\circ} \mathrm{C}$ & $1 \mathrm{hr}$. & 37.5 & 30.5 & 1.48 \\
\hline & $2 \mathrm{~T}$ & $500^{\circ} \mathrm{C}$ & $2 \mathrm{hrs}$. & Water & $155^{\circ} \mathrm{C}$ & $1 \mathrm{hr}$. & 35.2 & 30.2 & 1.6 \\
\hline & $9 \mathrm{~T}$ & $500^{\circ} \mathrm{C}$ & $2 \mathrm{hrs}$. & Water & $155^{\circ} \mathrm{C}$ & $4 \mathrm{hrs}$. & 37.3 & 30.6 & 1.31 \\
\hline & $9 \mathrm{~T}$ & $500^{\circ} \mathrm{C}$ & $2 \mathrm{hrs}$. & Water & $155^{\circ} \mathrm{C}$ & $4 \mathrm{hrs}$. & 38.1 & 30.6 & 1.13 \\
\hline & 0 & $500^{\circ} \mathrm{C}$ & $9 \mathrm{hrs}$. & Water & $155^{\circ} \mathrm{C}$ & $4 \mathrm{hrs}$. & 16.8 & 9.9 & 0.78 \\
\hline $\begin{array}{c}\text { 8Ce10Mg-T6 } \\
\text { CMI Project } \\
\text { Typical }\end{array}$ & 0 & $500^{\circ} \mathrm{C}$ & $5.75 \mathrm{hrs}$. & Water & $163^{\circ} \mathrm{C}$ & $4 \mathrm{hrs}$. & 32.0 & 24.5 & 2 \\
\hline
\end{tabular}




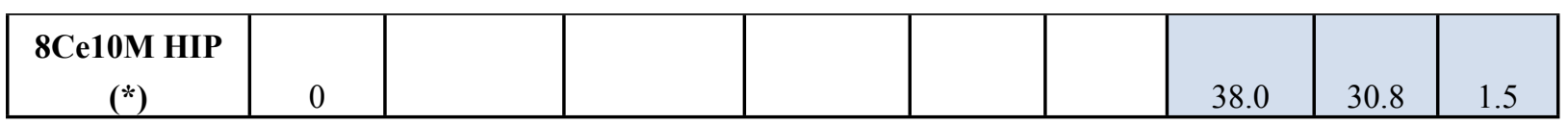

*HIP Processing $=432^{\circ} \mathrm{C} / 3$ hours, UTS $=$ Ultimate Tensile Strength, $\mathbf{Y S}=$ Yield Strength, $\% \mathbf{E l}=\%$ Elongation

\subsubsection{Results for Alloy 242}

Alloy 242 was thermomagnetically processed via a solutionizing $\left(516^{\circ} \mathrm{C}\right.$ for 2 hours $)$ and aging $\left(205^{\circ} \mathrm{C}\right.$ for 1 hour) treatment in a 9T field. In Figure 3, optical micrographs display the untreated (left) and thermomagnetically processed (right) microstructures. The most notable effect is in the dissolution of the copper-rich particles (eutectic phase) which previously decorated the grains in the untreated, as-cast condition. Normally, long (8-12 hour), high temperature $\left(530^{\circ} \mathrm{C}\right)$ solution treatment is required to dissolve the copper, which is then captured in a supersaturated solid solution during quench, followed by a 4 hour aging or precipitation treatment at $200^{\circ} \mathrm{C}$ designed to form a finely dispersed precipitate in the matrix and at the grain boundaries. Thermomagnetic processing (TMP) of this alloy accelerates that dissolution process and yields more solute in solid solution to form finer and more copious strengthening precipitates that would increase strength over non-TMP processed samples. Compared to handbook values of conventionally heat treated A242-T77 the yield strength of the TMP samples is high (Table 3) (up to 65\% for the Yield Strength) while elongation remains $>1 \%$. The combination of higher strength and equal ductility in a cast product suggests that a fine precipitate likely formed during aging due to the more homogeneous redistribution of solute atoms in the matrix during the solution treatment in the field.

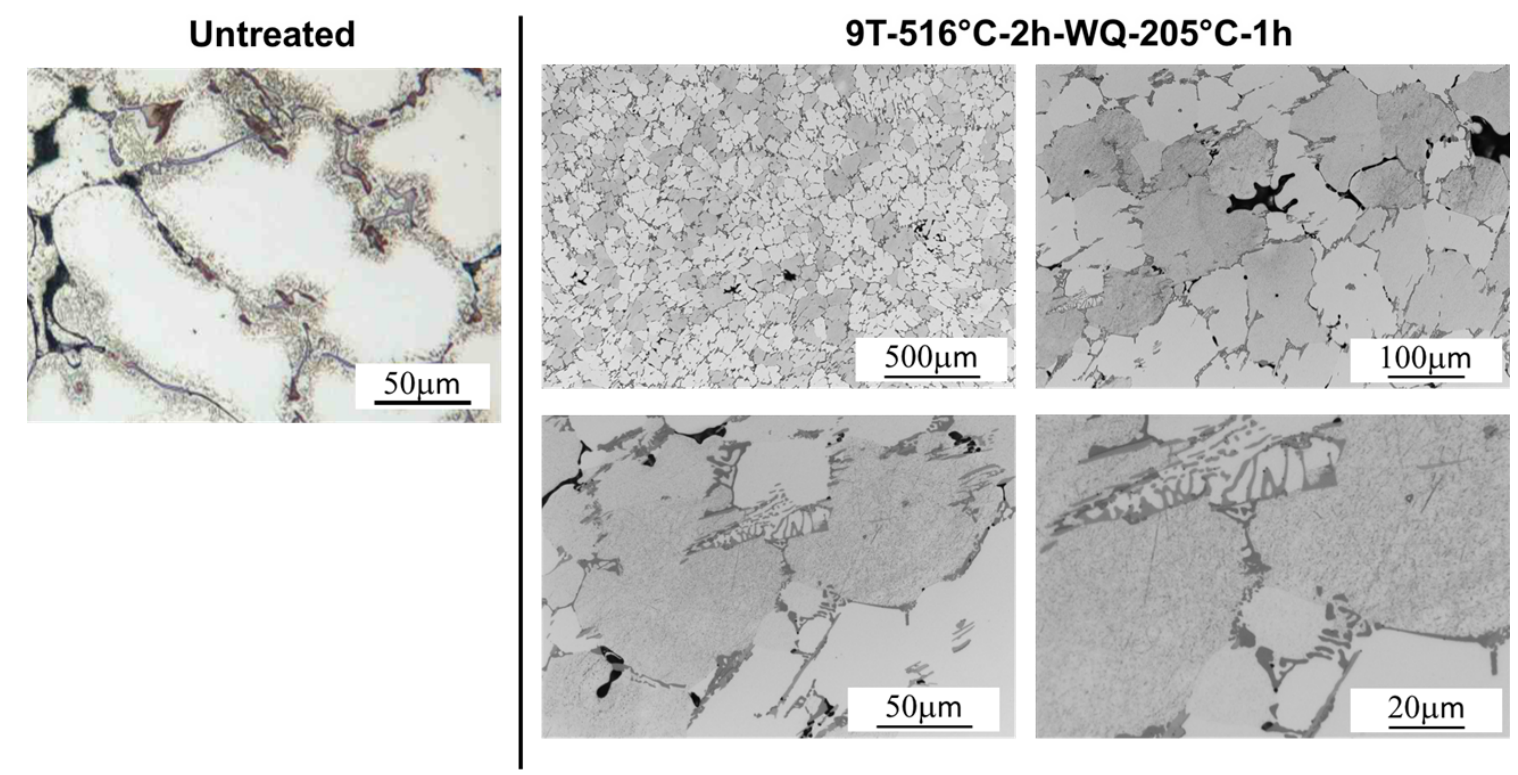

Figure 3. Optical micrographs of alloy 242 in the untreated (left) and thermomagnetically processed (right) conditions.

\subsubsection{Results for Alloy 355}

Alloy 355 in the $\mathrm{T} 6$ condition was also thermomagnetically processed via a solutionizing $\left(527^{\circ} \mathrm{C}\right.$ for 2 hours) and aging $\left(154^{\circ} \mathrm{C}\right.$ for 1 hour $)$ treatment in a 9T field. Typical literature mechanical properties for this alloy system are on the order of $25 \mathrm{ksi}$ for the YS, $35 \mathrm{ksi}$ for the UTS, and 3\% for elongation, so the TMP technology increases YS by nominally $16 \%$ while increasing UTS by $\sim 20 \%$. In Figure 4 , optical micrographs display the untreated (left) and thermomagnetically processed (right) 
microstructures. The precipitates that line the grain boundaries in the untreated sample become elongated along the grain boundaries in the TMP treated sample, though otherwise no coarsening is observed in the Al grains. Qualitatively, the volume fraction of grain boundary phase appears to be less in the TMP sample which suggests that increased solute in solid solution was achieved under a high magnetic field that allowed for fine and more copious precipitates forming in the aging process resulting in the increased strengths. Notably for both the 242 and 355 alloys processed via TMP, the heat treatment processing times are lower compared to normal commercial practice which would result in energy savings incorporating TMP into an industrial environment.

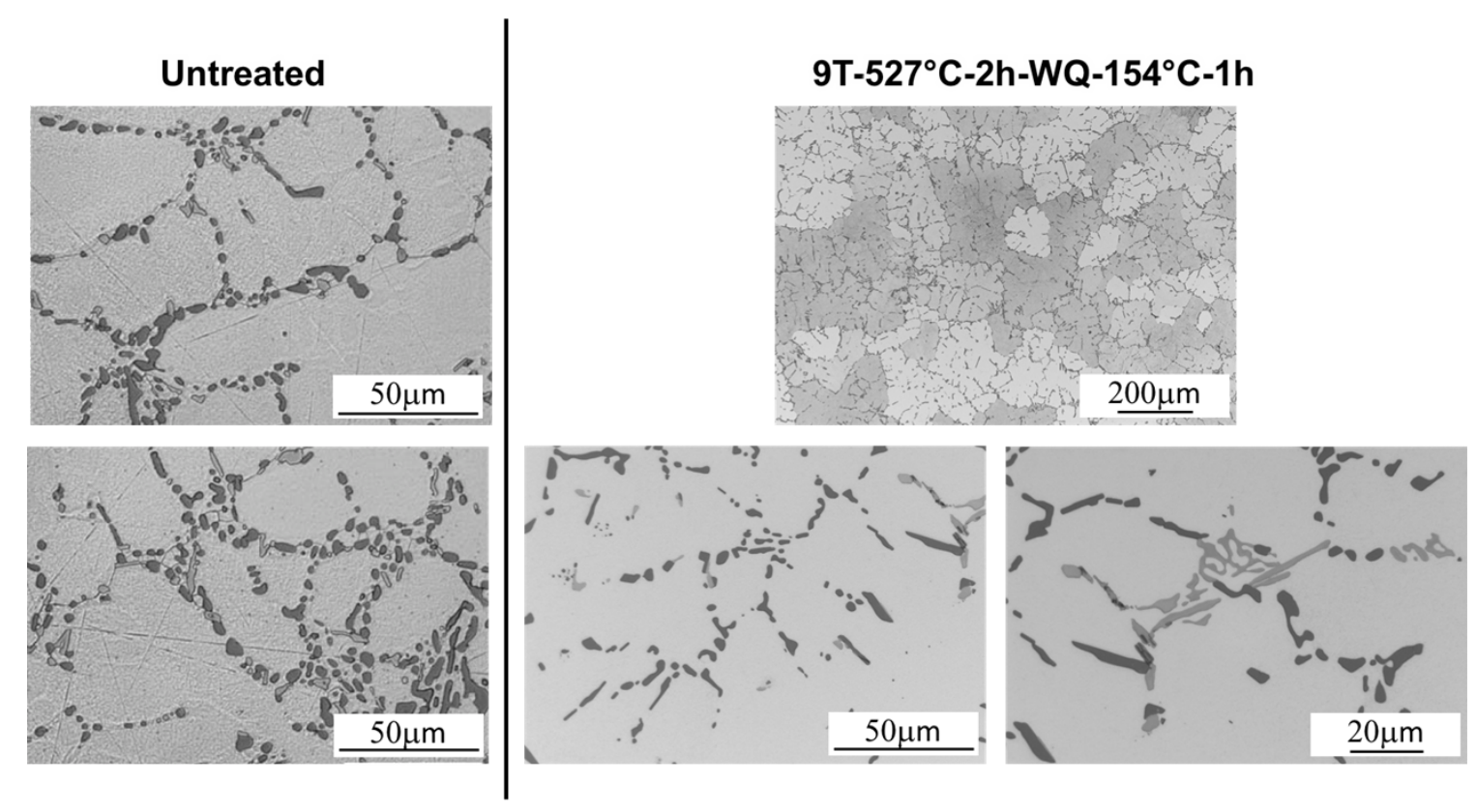

Figure 4. Optical micrographs of alloy 355-T6 in the untreated (left) and thermomagnetically processed (right) conditions.

\subsubsection{Results for Al-8Ce-10Mg Alloy}

A parametric study involving different high magnetic field strength levels $(2,5$, and $9 \mathrm{~T})$ was conducted on the Al-8Ce-10Mg alloy. This was done to determine the lowest magnetic field strength necessary to achieve the performance enhancements observed at the $9 \mathrm{~T}$ level. The data in Table 3 indicate that the $2 \mathrm{~T}$ level provides an industrially beneficial impact almost comparable to the $5 \mathrm{~T}$ level that exhibited the highest strength and ductility improvements in this study. From a commercial implementation/scalability perspective, the lowest magnetic field strength to achieve a cost-effective performance enhancement translates to the lowest cost superconducting magnet system required for the heat treating process line. The improvement observed at the $2 \mathrm{~T}$ level suggests that the majority of the property enhancement occurs approaching a threshold value of field strength that contributes most to the dissolution of solute during the solution heat treatment cycle, accelerates the solution heat treating and aging heat treatment processes, and achieves higher strengths after final aging in a field. This $2 \mathrm{~T}$ level appears to correlate to the observation that most non-ferromagnetic materials reach a magnetization saturation plateau in their B-H curves (magnetic flux density [B] versus magnetic field strength $[\mathrm{H}]$ ) by $2 \mathrm{~T}$. Beyond that point a very shallow slope is observed with increasing field strength.

Since comparable results were observed at all 3 field strength levels, the microstructural evaluation of the $2 \mathrm{~T}$ sample will be discussed in this report and will be compared with an as-cast sample as well as 
with a sample that received a Hot Isostatic Press (HIP) treatment under efforts in the CMI program. This particular $\mathrm{Al}-8 \mathrm{Ce}-10 \mathrm{Mg}$ sample was thermomagnetically processed via a solutionizing $\left(500^{\circ} \mathrm{C}\right.$ for 2 hours) and aging $\left(155^{\circ} \mathrm{C}\right.$ for 1 hour) treatment in a $2 \mathrm{~T}$ field. In Figure 5, optical (top) and Scanning Electron Microscopy Back Scattered Electron (SEM BSE) (bottom) micrographs show the effect of magnetic processing compared to the as-cast and HIP conditions. While the HIP and magnetic field treatments result in similarly enhanced tensile properties (Table 3), the differing effects on microstructure are evident. The BSE micrograph of the HIP microstructure (bottom-middle in Figure 5) shows particles distributed in and along grain boundaries, while the magnetically processed sample (bottom-right in Figure 5) appears similar to the as-cast microstructure (bottom-left in Figure 5). Optical micrographs in Figure 6 show that there is some evidence of grain boundary pinning of $\mathrm{Al}$ grains in the samples processed in the magnetic field. This again suggests that enhanced solute in solid solution is formed via TMP that subsequently precipitates throughout the matrix and along the grain boundaries. Further investigation is necessary to understand the microstructure at higher magnification. As is the case for tempering age hardening aluminum alloys, the mechanisms for the enhanced mechanical properties in the magnetically processed samples likely arise from microstructural features at a finer (tens of nanometers) scale than is observable with optical microscopy or SEM. Literature in the past decade (Liu, et al, [reference 1] and Watanabe, et al, [refernce 2]) suggest that a low frequency magnetic field and magnetic fields in general, from a grain boundary engineering perspective, can decrease grain boundary segregation, produce more homogensous distribution of hardening solute in the matrix phase, and result in more copious precipitation facilitating property enhancement as observed in this investigation.

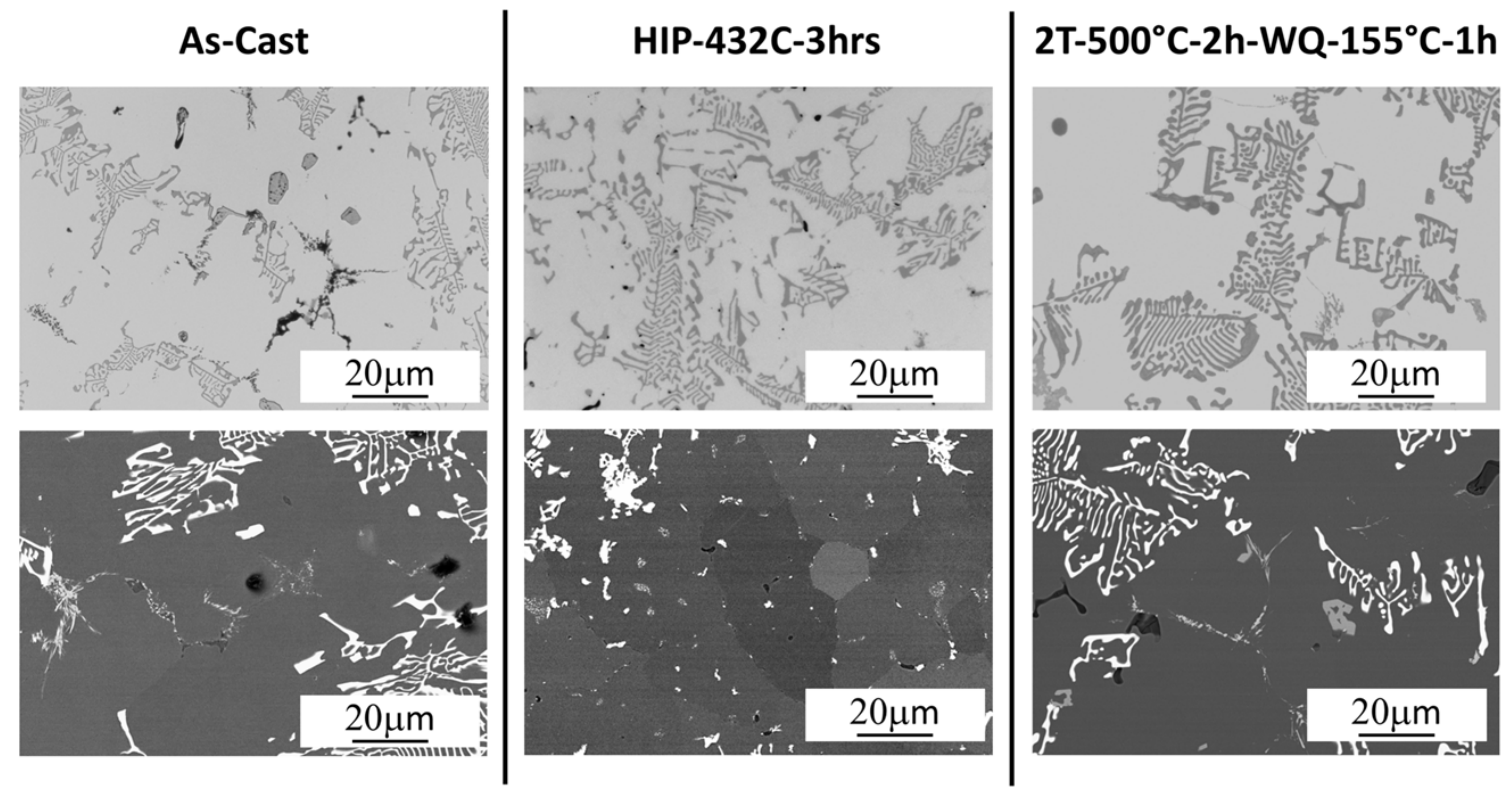

Figure 5. Optical (top) and SEM BSE (bottom) micrographs of alloy Al-8Ce-10Mg in the as-cast (left), HIP (middle), and thermomagnetically processed (right) conditions. 


\section{$2 \mathrm{~T}-500^{\circ} \mathrm{C}-2 \mathrm{~h}-\mathrm{WQ}-155^{\circ} \mathrm{C}-1 \mathrm{~h}$}
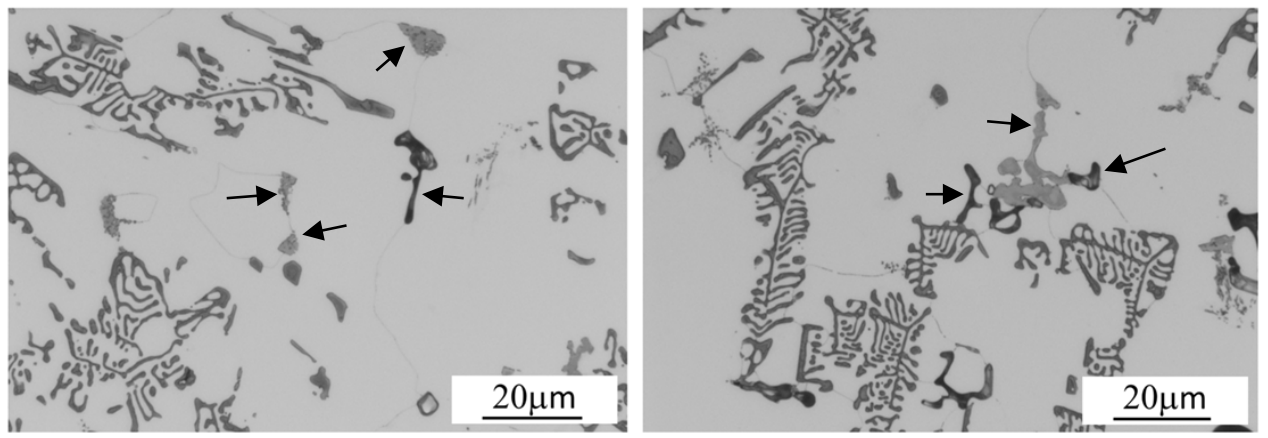

Figure 6. Optical micrographs of thermomagnetically processed alloy Al-8Ce-10Mg showing pinning (arrows along faint grain boundaries) of some $\mathrm{Al} / \mathrm{Al}$ grain boundaries.

A noteworthy microstructural observation in the HIP and 2T conditions is the effect of heat treatment on a Fe-rich phase that is present due to the small Fe concentration in the Al-8Ce-10Mg alloy. Figure 7 shows the morphology of this phase in the various conditions. The phase has a needle-like morphology that forms upon solidification in the cast structure. In the HIP condition at $432^{\circ} \mathrm{C}$, this phase begins to agglomerate with the adjacent needles after 3 hours and fully agglomerates and spheroidizes after 21 hours, while after thermomagnetic processing at $500^{\circ} \mathrm{C}$ for 2 hours, this phase remains needle-like similar to the cast structure. Of course, since the TMP process is being investigated for both energy savings during the heat treating process by dramatically reducing processing time as well as demonstrating enhanced tensile properties, processing times on the order of 21 hours were not evaluated under this CRADA.
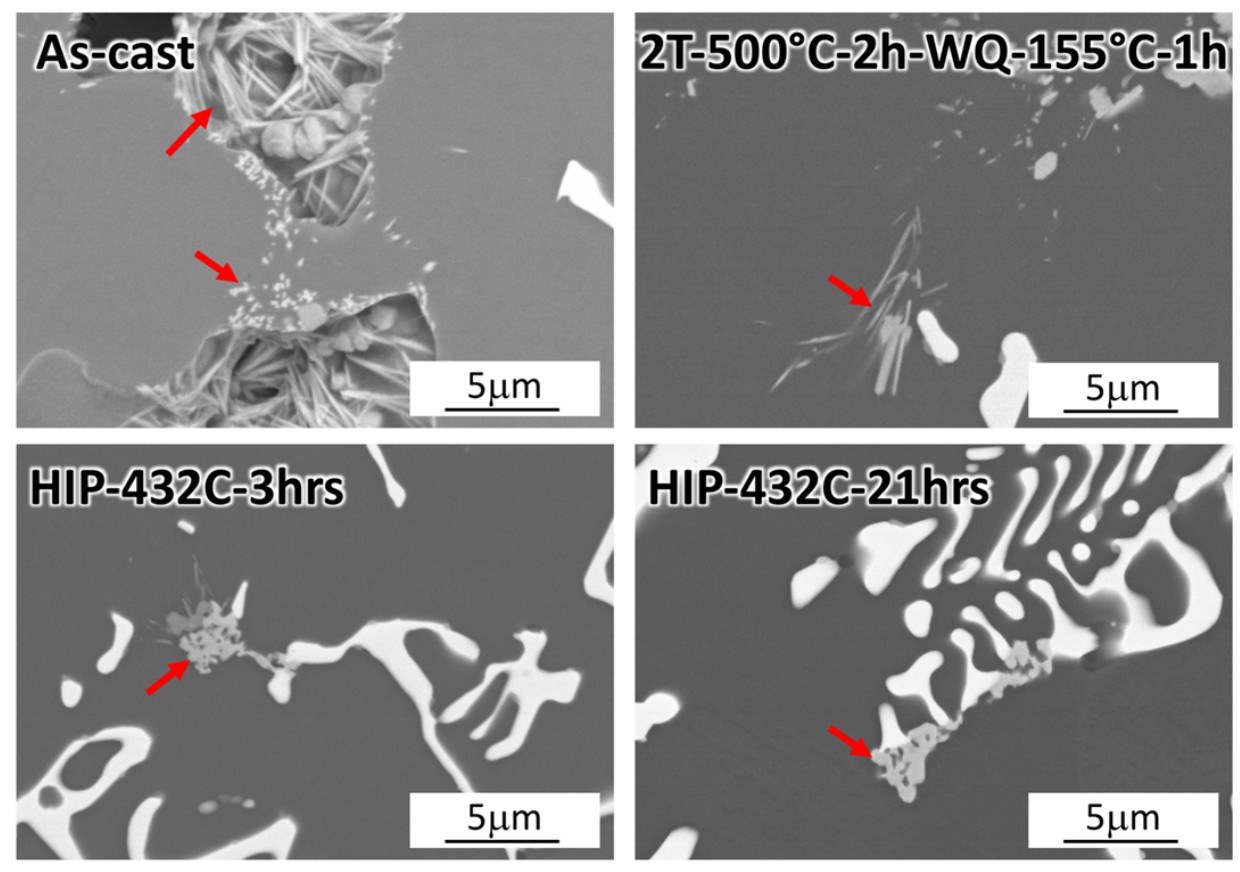

Figure 7. SEM BSE micrographs of alloy Al-8Ce-10Mg showing the effect of processing on the morphology of a Fe-rich phase. 
Throughout this discussion of the Al-8Ce-10Mg (and other alloys), accelerated dissolution of solute during the thermomagnetic processing treatments has been suggested as a mechanism for enabling a better aging response resulting in finer and more copious strengthening precipitates that typically are on the order of tens of nanometers and hence only visible in a Transmission electron microscopy(TEM) microstructural evaluation. This concept is somewhat supported by looking at the predicted phases present in this alloy as a function of temperature as shown in the ThermoCalc plot depicted in Figure 8. At the solution heat treating temperatures $(500 \mathrm{C})$ used in this study, the alloy is predicted to be single phase. This is an equilibrium prediction and does not reflect the kinetics required during a heat treatment cycle to achieve that microstructure once a given room temperature microstructure has developed upon solidification and cooling of the casting. The plot does show that at ambient temperature three distinct phases coexist, and it is those phases that need to dissolve to get all, or at least a significant amount, of the solute in solid solution to achieve the maximum strengthening response during the aging heat treatment cycle. The normally very lengthy solution heat treating times for aluminum alloys reflects the significant time to get some dissolution and therefore the thermomagnetic processing appears to accelerate the kinetics during solution heat treating as manifested by increased strength without loss of ductility after aging.

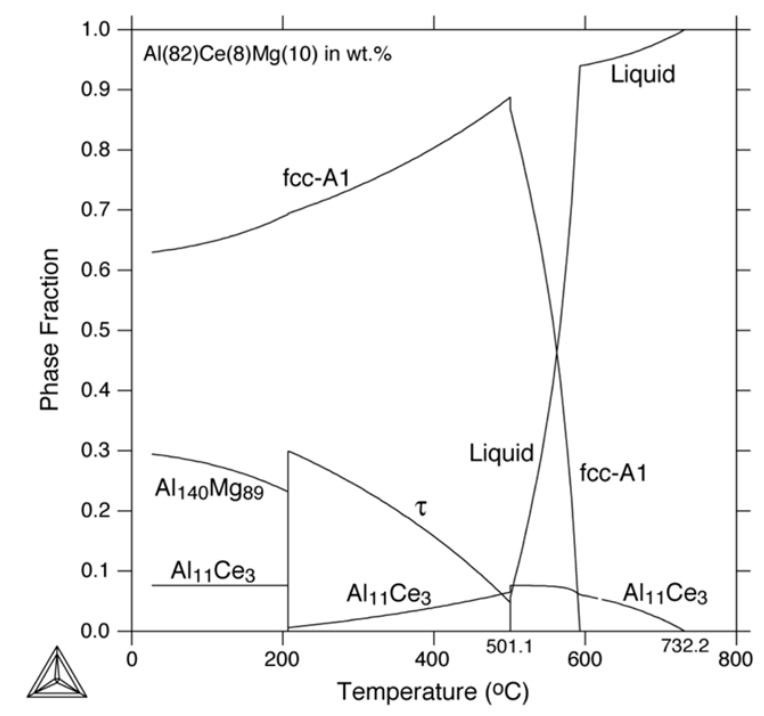

Figure 8. Phase fraction vs temperature diagram for the Al-8Ce-10Mg composition.

In conclusion, the results of this study on multiple different alloy systems clearly demonstrate that the TMP technology achieves, enhanced room temperature mechanical property performance at shorter processing times compared with conventional heat treating practices. Of significance from a commercial implementation perspective, magnetic fields on the order of $2 \mathrm{~T}$ appear to exhibit most of the beneficial effect as field strengths up to $9 \mathrm{~T}$ for the Al-8Ce-10Mg alloy which suggests this effect of lower field strength on enhanced performance may be the case for other age hardening aluminum alloy systems.

\subsection{Technology Commercialization Viability}

Since positive results from both a heat treating process energy efficiency and casting performance enhancement perspective have been shown for the different alloy systems using thermomagnetic processing, the viability for potential commercial system designs was evaluated. During Phase 1 
performance enhancement was observed using a $9 \mathrm{~T}$ magnetic field during heat treatment and so a large bore superconducting magnet system with that high field capability would be necessary. As seen in the concept drawing in Figure 9, a cryogen-free (conduction-cooled) 8-T superconducting high magnet field system is viable with a 16-inch diameter $(406 \mathrm{~mm})$ warm bore that would be able to handle both a heating insert and large components such as the cylinder head depicted in Figure 1.

This Phase 2 effort has demonstrated that magnetic field strengths of only $2 \mathrm{~T}$ are required to see some benefit. Superconducting system design becomes tremendously easier and significantly less expensive at low field strengths such as $2 \mathrm{~T}$ compared with 8 or $9 \mathrm{~T}$. Therefore, the 2-T, 24-inch diameter warm bore recondensing cryocooler superconducting magnet design from American Magnetics, Inc. shown in Figure 10 is extremely viable. That design concept readily allows for increasing the length of the uniform field zone to accommodate samples with industrial-scale dimensions in all directions. Although shown with a horizontal bore, the system could easily be built with a vertical bore to allow rapid dropping of the sample into a quench medium if required, or accommodating both a heating and quenching insert in the magnet bore itself. A system shown in Figure 10 would cost nominally on the order of $\$ 700 \mathrm{~K}$ to $\$ 800 \mathrm{~K}$ to fabricate. One important aspect of superconducting magnet systems is that they can be set to persistent mode to any magnetic field strength from zero up to their maximum magnetic field design value so procuring a system capable of higher magnetic field strengths can be used to cover several different field strength needs in a production environment.
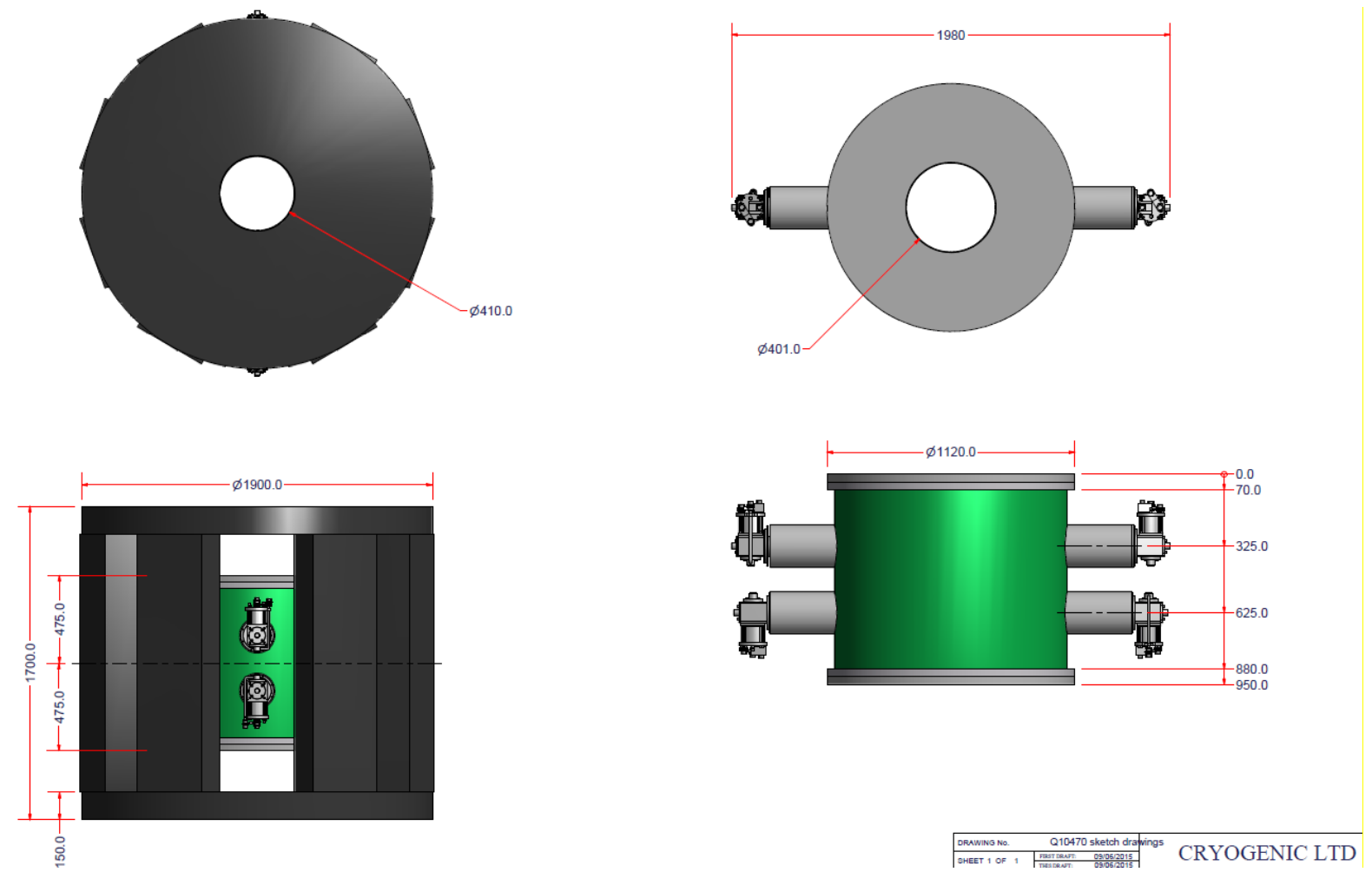

Figure 9 Concept drawing provided by Cryogenic Limited for an 8-tesla, cryogen-free (conduction cooled) 16-inch $(406 \mathrm{~mm})$ diameter warm-bore superconducting magnet system. 


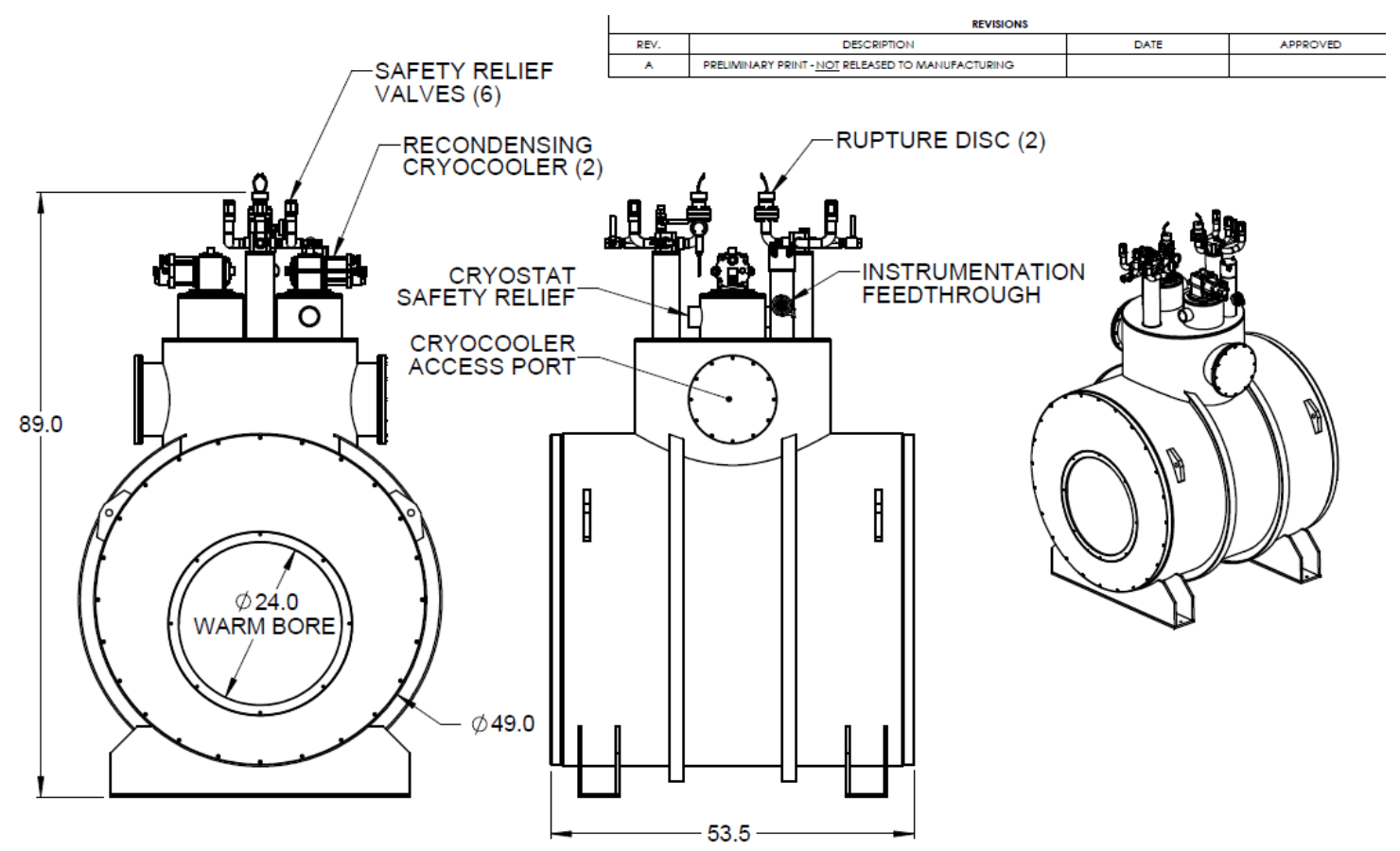

Figure 10 Concept drawing provided by AMI, Inc. for a 2-tesla, recondensing cryocooler-based, 24-inch $(610 \mathrm{~mm})$ diameter warm-bore superconducting magnet system.

\subsection{IMPACTS}

Magnetic processing of aluminum castings could create significant savings in the manufacturing of light weight auto parts especially through energy savings up to $80 \%$ through reductions in heat treatment times. This impact is extremely relevant to the mission of EERE/AMO. Additionally this technology will contribute to transportation fuel savings by enabling lighter weight vehicles by replacing heavier steel components with enhanced performance, lighter weight aluminum parts. The results of this endeavor clearly document the enhanced performance and energy savings potential of thermomagnetically processing cast (or wrought) aluminum alloys during either just the solution heat treatment cycle or both the solution heat treating and aging process. The generation of more statistical, parametric study information for multiple cast aluminum alloy families would be very beneficial and necessary to support a commercialization decision.

\subsection{CONCLUSIONS}

Thermomagnetic processing (TMP) during solution heat treating and aging of three different cast aluminum alloys $(242,355$, and Al-8Ce-10Mg) resulted in increases in yield strength (YS) ranging from 10 to $65 \%$ and ultimate tensile strength (UTS) increases of 16 to $37 \%$ over reported conventional heat treatment practice values. All of the TMP solution heat treating and aging times employed in this study were for times significantly shorter than those conventionally required by industrial practice to achieve performance exceeded by the TMP alloys. This indicates this technology could achieve significant energy savings when implemented in a production heat treating environment. Microstructural analyses suggest that the high magnetic fields enable faster dissolution of solute during the solution heat treating cycle that would be manifest as finer and more copious strengthening precipitates after the aging cycle which would explain the increase in YS and UTS without loss of ductility via TMP.

Large-bore superconducting magnet systems that could handle production scale parts can be obtained in the marketplace which indicates commercial implementation of TMP, especially at the $2 \mathrm{~T}$ 
magnetic field level, can be realized if a return-on-investment calculation supported that path forward for a specific business sector. The results of this study on multiple different alloy systems clearly demonstrate that the TMP technology achieves excellent, enhanced room temperature mechanical property performance at significantly shorter processing times compared with conventional heat treating practices. Of significance from a commercial implementation perspective, magnetic fields on the order of $2 \mathrm{~T}$ appear to have the same beneficial effect as field strengths up to 5 and $9 \mathrm{~T}$ for the Al$8 \mathrm{Ce}-10 \mathrm{Mg}$ alloy which suggests this $2 \mathrm{~T}$ magnetic field strength may improve mechanical properties of other age hardening aluminum alloy systems for both cast and wrought product.

\subsection{REFERENCES}

1. Liu, X., Cui, J., Wang, E., \& and He, J. (2005). Influence of a Low-Frequency Electromagnetic Field on Precipitation Behavior of a High Strength Aluminum Alloy. Marerials Science and Engineering A, 1-4.

2. Watanabe, T., Tsurekawa, S., Zhao, X., Zuo, L., \& and Esling, C. (2006). A New challenge: Grain boundary Engineering for Advanced Materials by Magnetic field Application". Journal of Materials Science, 7747-7759. 


\section{ECK INDUSTRIES, INC. BACKGROUND}

Eck Industries, Inc. is a privately-owned fourth generation family business with over 64 years of experience in the aluminum foundry industry. Eck delivers aluminum castings to customers in the military, hybrid vehicles, commercial trucking, aerospace, medical, industrial and energy markets.

Eck was incorporated as Eck Foundries, Inc. in May 1948. The business was built on orders from Harley-Davidson, Wisconsin Motors, West Bend Outboard and Johnson Motors. From 1948 to 2010 Eck grew from operating in a 7,200 square foot garage with 8 employees and 5 customers to a plant with 210,000 square feet, over 250 employees and 110 customers.

Eck Industries Inc. was awarded the Casting of the Year by the American Foundry Society for a challenging hybrid driveline housing that was successfully converted from a fabrication in 2011, and was recognized in 2012 by Modern Casting magazine as the Metalcaster of the Year for innovations in alloys, processes and application development. 